RESEARCH ARTICLE

\title{
Genetic Polymorphism of Glutathione S-transferase and Cervical Cancer Susceptibility in Northeastern Thailand
}

\author{
Wannapa Settheetham-Ishida ${ }^{1}$, Mayuree Wongpratate ${ }^{1}$, Sophida Phuthong ${ }^{1}$, \\ Sitakan Natphopsuk ${ }^{2}$, Takafumi Ishida ${ }^{3}$
}

${ }^{1}$ Department of Physiology, Faculty of Medicine, Khon Kaen University, Khon Kaen, Thailand. ${ }^{2}$ Chulabhorn International College of Medicine, Thammasat University, Thailand. ${ }^{3}$ Department of Biological Sciences, Graduate School of Science, the University of Tokyo, Tokyo, Japan.

\begin{abstract}
Background: Exposure to certain carcinogens together with host genetic predisposition likely has an influence on cervical carcinogenesis. Objective: Our aim was to evaluate synergistic effects of glutathione S-transferase (GST) polymorphisms and risk behaviors (i.e., smoking and contraceptive use) on squamous cell cervical cancer (SCCA) development in northeastern Thailand. Methods: Subjects were 198 (SCCA) patients and 198 age-matched healthy controls. Multiplex PCR and PCR-RFLP were used to determine GSTT1 and GSTA1 gene polymorphism, respectively. Results: Interaction between the four polymorphic loci of GSTS (GSTM1, GSTT1, GSTP1 and GSTA1) and increased risk for cervical cancer was not observed. The three genotypes of GSTM1 consistently showed significant risks of smoking with a lower OR for the Null individuals (1.741) at around one -fourth of wild type homozygous individuals (8.000). The effects of GST polymorphisms on cervical cancer risk under the use of hormonal contraceptives apparently did not occur. Conclusions: The predisposition of smoking risk is related to the GST genotype. It is suggested that knowing one's own genotype data will contribute to the prevention of SCCA by controlling risk habits.
\end{abstract}

Keywords: Polymorphism- genetic- glutathione S-transferase- cervical cancer- Northeastern Thailand

Asian Pac J Cancer Biol, 5 (2), 35-41

\section{Introduction}

Cervical cancer remains the most common cancer and the leading cause of cancer-related deaths among women worldwide [1], including in Thailand [2]. Cervical cancer is usually considered to be caused by human papillomavirus (HPV) infection [3]. Nowadays, preventive HPV vaccines are available but these vaccines are effective in clearing only certain types of HPV infection. Other risk factors such as chemical substances and genetic backgrounds might be associated with risk of cervical cancer development. Tobacco smoke contains numerous carcinogens [4]; polycyclic aromatic hydrocarbons (PAHs), and volatile $\mathrm{N}$-nitrosamines; all of which are considered to be primary carcinogens [5].

Smoking exposure is a leading cause of many types of cancer such as of lung and cervix [6-7]. Estrogencontaining oral contraceptives might affect carcinogenesis
Submission Date: 02/12/2020Ａcceptance Date: 05/02/2020 
between reduced glutathione (GSH) and substances (including environmental xenobiotics, carcinogens, chemotherapeutic agents or products of oxidative stress) [10]. These metabolizing enzymes are encoded by the glutathione-S-transferase genes (GSTS). Eight classes of cytosolic GST (corresponding gene) are recognized in mammalian species (viz., alpha (GSTA), mu (GSTM), theta (GSTT), pi (GSTP), sigma (GSTS), kappa (GSTK), omega (GSTO), and zeta (GSTZ) [12]. Allelic variants of the GSTS result in altered detoxification efficiency and are found to be polymorphic in many human populations [13]. It is thus agreeable to assume allelic variants of GSTS affect respective carrier susceptibility to various diseases including cancers [14].

Polymorphism of these genes results in alteration of enzymatic activity. For example, the $T T$ genotype of the GSTA1 single nucleotide polymorphism (SNP) T69C had a lower enzymatic activity compared to the $C C$ genotype [15]. A functional polymorphism of the GSTP1 at codon 105 contributes to the change of enzymatic stability and activity of the hydrophobic substrate binding site or electrophile-binding active site of the GST Pi peptide [16]. It has been reported that product of the Val allele has less conjugation capacity than that of the Ile allele [17]. GSTM1 and GSTT1 have a common and broad range of substrate specificities and as such they detoxify the reactive metabolites of benzo-a-pyrene and other polycyclic aromatic hydrocarbons [18]. A complete deletion of the GSTM1-which is frequently found in several populations - results in a null (homozygous) or partial loss (heterozygous) of enzymatic activity [19]. Several studies have reported that the homozygous deletion type of the GSTM1 is correlated with several types of cancer (i.e., colorectal, head and neck, lung, breast and prostate) [20]. A number of investigations have not, however, found any association between GSTM1 polymorphism and cancers [10-11]. The complete absence of enzymatic activity caused by a homozygous status (null genotype) of the GSTT1 deleted allele has been reported to increase the risk of prostate and colorectal cancers [21-22]. To contrast, the null genotype of the GSTT1 was not significantly associated with an elevated risk of gastric and colorectal cancer in the Korean population nor any cervical abnormality in a multi-ethnic population [23-24].

With the aim of preventing or reducing the incidence of squamous cell carcinomas of the cervix (SCCA) among Northeastern Thai women, we conducted several epidemiological studies and found that HPV infection, smoking habit, and sexual behavior were the major risks for the development of SCCA [25]. As for the potential co-risk factors, we focused on genetic predispositions related to the GSTs and performed genotyping of the GSTM1 and GSTP1 [26-27]. In the current study, we added the GSTT1 and GSTA1 genotype data and re-evaluated for any synergistic effects of the four GST polymorphisms and the risk behaviors (i.e., smoking and contraceptive use on the SCCA development).

\section{Materials and Methods}

\section{Study subjects}

This case-control study comprised 198 cases of pathologically-confirmed SCCA and 198 age-matched healthy volunteers (within 5 years) with normal cytology and histology. The participants were recruited from Khon Kaen General Hospital and Srinagarind Hospital, Khon Kaen Province, Northeast Thailand, between February 2009 and August 2011. Data on the passive exposure to tobacco smoke and high-risk HPV infection were shared in previous studies [6-25]. All of the participants were informed about the purpose and methodology of the research and each signed informed consent prior to enrollment. The study was reviewed and approved by the Ethics Committee of Khon Kaen University (HE 450333) and Khon Kaen Hospital (No.03/02/2554). Data on the passive exposure to tobacco smoke and oral contraceptive use were documented in two previous studies [6-25].

\section{DNA extraction and genotyping}

The peripheral blood samples were taken and kept in EDTA tubes from both the patient and control groups. Genomic DNA extraction was performed using the GF-1 Blood DNA Extraction Kit (Vivantis, USA).

GSTT1 polymorphism was detected using the multiplex PCR method with the following two primer pairs: 5'-CAGTTGTGAGCCACCGTACCC-3', and 5'-CGATAGT T GC T GGCCCCCTC-3', 5'-CCAGCTCACCGGATCATGGCCAG-3' and 5'-CCTTCCTTACTGGTCCTCACATCTC-3'. The PCR mixture was performed using a total volume of $25 \mu \mathrm{l}$, containing $1 \mu \mathrm{l}$ of DNA template, $12.5 \mu \mathrm{l}$ of KOD buffer, $5 \mu \mathrm{l}$ of dNTP, $0.2 \mathrm{mM}$ of each primer, and 0.5 unit of KOD FX (Toyobo, Japan). The cycle condition follows: an initial denaturation at $94^{\circ} \mathrm{C}$ for $2 \mathrm{~min}$, followed by 30 cycles of denaturation at $98^{\circ} \mathrm{C}$ for $10 \mathrm{sec}$, and annealing and extension at $68^{\circ} \mathrm{C}$ for $90 \mathrm{sec}$. The PCR product (1460 bp and/or $466 \mathrm{bp}$ ) was analyzed by electrophoresis on $1.5 \%$ agarose gels.

The GSTA1 C69T polymorphism was determined using the PCR-RFLP method. The sequences for the primer pair were: 5'-GCA TCA GCT TGC CCT TCA-3' and 5'-AAA CGC TGT CAC CGT CCT G 3'. The PCR product of the 400-bp long was digested by EarI (New England, USA) and electrophoresed on $2.5 \%$ agarose gel (Vivantis, USA), then visualized using ethidium bromide staining. The $T$ allele generates a 308 bp and 92 bp fragment, while the $C$ allele remains uncut.

The genotyping data for GSTM1 and GSTP1 were adapted from Natphopsuk et al. [26] and Phuthong et al. [27], respectively.

\section{Statistical analysis}

The genotype distribution was tested using the Hardy-Weinberg equilibrium. The genotype and allele frequencies between the cases and controls were compared using the $\chi 2$ test with Yates' correction when required. The associations between selected variables and risks for SCCA were represented using the odds ratio (OR) with 
a $95 \%$ CI by using StataSE for the uni- and multi-variate logistic regression analyses. Differences were considered statistically significant when the P-value was $<0.05$.

\section{Results}

Genotype distribution and allele frequency of each GST polymorphism (GSTT1, GSTA1, GSTM1, and GSTP1) are presented in Table 1. No significant deviation from the Hardy-Weinberg equilibrium in the genotype distribution among the controls was observed $(\mathrm{P}>0.05$ by $\chi 2$ test). There was no sign of altered risks for the development of cervical cancer except for the GSTP1 G allele; for which the presence resulted in a reduction of risk [33]. Interaction between the four polymorphic loci of GSTS (GSTT1, GSAT1, GSTM1, and GSTP1) and an increased risk for cervical cancer was not observed (data not shown).

Polymorphisms of GST, moreover, are associated with a higher risk of developing cervical cancer among smoking women [28]. In the present study, the effects of GST polymorphisms on cervical cancer risk vis-à-vis the sexual partner's tobacco smoking were inconclusive in a standard case-control comparison, $\mathrm{P}>0.05$ (Table 2). Our previous study confirmed that passive smoking was itself associated with a significantly increased risk of cervical cancer among northeastern Thai women [6]. Accordingly, we evaluated the degree of risk of smoking (passive) vis-à-vis each genotype-based subpopulation to determine whether or not any genetic predisposition existed (Table 3). The effects of GST polymorphisms on cervical cancer risk under the use of hormonal contraceptives apparently did not occur (Table 4); however, it should be noted that the individuals with the GSTT1 null genotype were found to show a trend of increase in cervical cancer risk among women taking oral contraceptives (adjusted OR: 4.25 (95\% CI=1.00-18.01, $\mathrm{P}=0.050)$. We could not find any altered risk by the use of oral contraceptives in each genotype-based sub population (data not shown).

\section{Discussion}

The frequency of the GSTT1 null genotype (35.86\%) was similar to previous reports among Asian population (30.0-41.4\%) [29-31]. The finding in the current study of no relationship between the GSTT1 deletion type and risk of cervical cancer agreed with other reports among various Asian and European populations [28-32]. Few studies have reported a significant correlation between the GSTT1 null genotype and cervical cancer [33]; however,

Table 1. Each GST Polymorphism and Risk for Cervical Cancer

\begin{tabular}{|c|c|c|c|c|}
\hline GST Genotypes & Controls n $(\%)$ & Cases n $(\%)$ & Crude OR $[95 \% \mathrm{CI}, P]$ & Adjusted $\mathrm{OR}^{\mathrm{a}}[95 \% \mathrm{CI}, P]$ \\
\hline \multicolumn{5}{|l|}{ GSTT1 } \\
\hline$+/+$ & $34(17.17)$ & $34(17.17)$ & 1 & 1 \\
\hline$+/-$ & $93(46.97)$ & $100(50.51)$ & $1.08[0.60-1.94,0.7970]$ & $1.43[0.62-3.29,0.401]$ \\
\hline$-/-$ & $71(35.86)$ & $64(32.32)$ & $0.90[0.48-1.68,0.7272]$ & $1.26[0.52-3.04,0.603]$ \\
\hline Present allele & 0.41 & 0.42 & 1 & NA \\
\hline Null allele & 0.59 & 0.58 & $1.08[0.81-1.43,0.6653]$ & NA \\
\hline \multicolumn{5}{|l|}{ GSTA1 } \\
\hline $\mathrm{CC}$ & $141(71.21)$ & $147(74.24)$ & 1 & 1 \\
\hline $\mathrm{CT}$ & $53(26.77)$ & $43(21.72)$ & $0.78[0.48-1.27,0.2888]$ & $0.78[0.39-1.54,0.468]$ \\
\hline $\mathrm{TT}$ & $4(2.02)$ & $8(4.04)$ & $1.92[0.50-8.88,0.2886]$ & $1.15[0.21-6.25,0.868]$ \\
\hline $\mathrm{C}$ allele & 0.85 & 0.85 & 1 & NA \\
\hline T allele & 0.15 & 0.15 & $0.96[0.65-1.42,0.8429]$ & NA \\
\hline \multicolumn{5}{|c|}{ GSTM1 (Natphopsuk et al., 2015) } \\
\hline$+/+$ & $15(7.58)$ & $15(7.58)$ & 1 & 1 \\
\hline$+/-$ & $58(29.29)$ & $53(26.77)$ & $0.91[0.38-2.22,0.8266]$ & $1.48[0.41-5.31,0.549]$ \\
\hline$-/-$ & $125(63.13)$ & $130(65.66)$ & $1.04[0.45-2.39,0.9191]$ & $1.16[0.35-3.86,0.801]$ \\
\hline Present allele & 0.22 & 0.21 & 1 & NA \\
\hline Null allele & 0.78 & 0.79 & $0.93[0.66-1.30,0.7298]$ & NA \\
\hline \multicolumn{5}{|c|}{ GSTP1 (Phuthong et al., 2018) } \\
\hline $\mathrm{AA}$ & $90(45.45)$ & $112(56.57)$ & 1 & 1 \\
\hline $\mathrm{AG}$ & $85(42.93)$ & $71(35.86)$ & $0.67[0.43-1.04,0.0623]$ & $0.55[0.29-1.04,0.068]$ \\
\hline GG & $23(11.62)$ & $15(7.58)$ & $0.52[0.24-1.12,0.0704]$ & $0.53[0.19-1.46,0.218]$ \\
\hline $\mathrm{AG}$ and $\mathrm{GG}$ & $108(54.55)$ & $86(43.43)$ & $0.64[0.42-0.97,0.027 *]$ & $0.55\left[0.30-0.99,0.048^{*}\right]$ \\
\hline A allele & 0.67 & 0.74 & 1 & NA \\
\hline G allele & 0.33 & 0.26 & $0.69\left[0.50-0.95,0.019^{*}\right]$ & NA \\
\hline
\end{tabular}

${ }^{a}$ adjusted multiple logistic regression for partner's smoking, oral contraceptive use and HPV infection NA, not applicable; *P value $<0.05$ 
Table 2. GST Polymorphisms and Risk for Cervical Cancer among Passive Smokers

\begin{tabular}{|c|c|c|c|c|}
\hline GST Genotypes & Controls n (\%) & Cases n $(\%)$ & Crude OR $[95 \% \mathrm{CI}, P]$ & Adjusted $\mathrm{OR}^{\mathrm{a}}[95 \% \mathrm{CI}, P]$ \\
\hline \multicolumn{5}{|l|}{ GSTT1 } \\
\hline$+/+$ & $19(18.73)$ & $28(19.58)$ & 1 & 1 \\
\hline$+/-$ & $55(57.14)$ & $67(46.85)$ & $0.83[0.42-1.64,0.585]$ & $1.07[0.37-3.13,0.904]$ \\
\hline$-/-$ & $33(24.49)$ & $48(33.57)$ & $0.99[0.47-2.05,0.972]$ & $1.95[0.61-6.20,0.257]$ \\
\hline \multicolumn{5}{|l|}{ GSTA1 } \\
\hline $\mathrm{CC}$ & $76(38.38)$ & $109(55.05)$ & 1 & 1 \\
\hline $\mathrm{CT}$ & $29(14.65)$ & $29(14.65)$ & $0.70[0.39-1.26,0.233]$ & $0.83[0.34-2.05,0.689]$ \\
\hline $\mathrm{TT}$ & $2(1.01)$ & $5(2.53)$ & $1.74[0.33-9.22,0.513]$ & $0.71[0.08-6.02,0.753]$ \\
\hline \multicolumn{5}{|l|}{ GSTM1 } \\
\hline$+/+$ & $5(4.67)$ & $12(8.39)$ & 1 & 1 \\
\hline$+/-$ & $27(25.23)$ & $37(25.87)$ & $0.57[0.18-1.81,0.342]$ & $1.13[0.20-6.45,0.890]$ \\
\hline$-/-$ & $75(70.09)$ & $94(65.73)$ & $0.52[0.18-1.55,0.241]$ & $0.67[0.13-3.40,0.630]$ \\
\hline \multicolumn{5}{|c|}{ GSTP1 (Phuthong et al., 2018) } \\
\hline AA & $49(45.79)$ & $77(53.85)$ & 1 & 1 \\
\hline AG & 43 (40.19) & $55(38.46)$ & $0.81[0.48-1.39,0.452]$ & $0.79[0.35-1.79,0.577]$ \\
\hline GG & $15(14.02)$ & $11(7.69)$ & $0.47[0.20-1.10,0.081]$ & $0.75[0.21-2.71,0.663]$ \\
\hline
\end{tabular}

adjusted multiple logistic regression for partner's smoking, oral contraceptive use and HPV infection

Table 3. Risk Evaluation of Smoking by GSTs Genotype

\begin{tabular}{|c|c|c|c|c|}
\hline GST Genotypes & Smoking status & Controls & Cases & Crude OR $[95 \% \mathrm{CI}, P]$ \\
\hline \multicolumn{5}{|l|}{ GSTT1 } \\
\hline \multirow[t]{2}{*}{$+/+$} & Non-smoking & 15 & 6 & 1 \\
\hline & Smoking & 19 & 28 & $3.684[1.21-11.20,0.0182 *]$ \\
\hline \multirow[t]{2}{*}{$+/-$} & Non-smoking & 38 & 33 & 1 \\
\hline & Smoking & 55 & 67 & $1.403[0.78-2.52,0.2579]$ \\
\hline \multirow[t]{2}{*}{$-/-$} & Non-smoking & 38 & 16 & 1 \\
\hline & Smoking & 33 & 48 & $3.455[1.66-7.19,0.0007 * *]$ \\
\hline \multicolumn{5}{|l|}{ GSTA1 } \\
\hline \multirow[t]{2}{*}{$\mathrm{CC}$} & Non-smoking & 65 & 38 & 1 \\
\hline & Smoking & 76 & 109 & $2.453[1.49-4.03,0.0003 * *]$ \\
\hline \multirow[t]{2}{*}{$\mathrm{TC}$} & Non-smoking & 24 & 14 & 1 \\
\hline & Smoking & 29 & 29 & $1.714[0.74-3.96,0.2049]$ \\
\hline \multirow[t]{2}{*}{ TT } & Non-smoking & 2 & 3 & 1 \\
\hline & Smoking & 2 & 5 & $1.667[0.15-18.87,0.6788] \#$ \\
\hline \multicolumn{5}{|l|}{ GSTM1 } \\
\hline \multirow[t]{2}{*}{$+/+$} & Non-smoking & 10 & 3 & 1 \\
\hline & Smoking & 5 & 12 & $8.000[1.52-42.04,0.0099 *]$ \\
\hline \multirow[t]{2}{*}{$+/-$} & Non-smoking & 31 & 16 & 1 \\
\hline & Smoking & 27 & 37 & $2.655[1.22-5.80,0.0132 *]$ \\
\hline \multirow[t]{2}{*}{$-/-$} & Non-smoking & 50 & 36 & 1 \\
\hline & Smoking & 75 & 94 & $1.741\left[1.03-2.94,0.0377^{*}\right]$ \\
\hline \multicolumn{5}{|l|}{ GSTP1 } \\
\hline \multirow[t]{2}{*}{ AA } & Non-smoking & 41 & 35 & 1 \\
\hline & Smoking & 49 & 77 & $1.841[1.04-3.28,0.0307 *]$ \\
\hline \multirow[t]{2}{*}{$\mathrm{AG}$} & Non-smoking & 42 & 16 & 1 \\
\hline & Smoking & 43 & 55 & $3.358\left[1.67-6.77,0.0005^{* *}\right]$ \\
\hline \multirow[t]{2}{*}{ GG } & Non-smoking & 8 & 4 & 1 \\
\hline & Smoking & 15 & 11 & $1.467[0.35-6.13,0.8657] \#$ \\
\hline
\end{tabular}


Table 4. GST Polymorphisms and Oral Contraceptive Use

\begin{tabular}{|c|c|c|c|c|}
\hline GST Genotypes & Controls n (\%) & Cases n $(\%)$ & Crude OR $[95 \% \mathrm{CI}, P]$ & Adjusted ORa $[95 \% \mathrm{CI}, P]$ \\
\hline \multicolumn{5}{|l|}{ GSTT1 } \\
\hline$+/+$ & $14(17.50)$ & $14(14.89)$ & 1 & 1 \\
\hline$+/-$ & $40(50.00)$ & $48(51.06)$ & $1.20[0.51-2.81,0.675]$ & $2.97[0.78-11.32,0.110]$ \\
\hline$-/-$ & $26(32.50)$ & $32(34.04)$ & $1.23[0.50-3.04,0.652]$ & $4.25[1.00-18.01,0.050]$ \\
\hline \multicolumn{5}{|l|}{ GSTA1 } \\
\hline $\mathrm{CC}$ & $58(29.29)$ & $70(35.35)$ & 1 & 1 \\
\hline $\mathrm{CT}$ & $22(11.11)$ & $21(10.61)$ & $0.79[0.40-1.58,0.506]$ & $0.65[0.23-1.79,0.400]$ \\
\hline $\mathrm{TT}$ & $0(0.00)$ & $3(1.52)$ & $-b$ & $-b$ \\
\hline \multicolumn{5}{|l|}{ GSTM1 } \\
\hline$+/+$ & $5(6.25)$ & $8(8.51)$ & 1 & 1 \\
\hline$+/-$ & $17(21.25)$ & $24(25.53)$ & $0.88[0.25-3.17,0.848]$ & $1.46[0.23-9.50,0.689]$ \\
\hline$-/-$ & $58(72.50)$ & $62(65.96)$ & $0.67[0.21-2.16,0.500]$ & $0.93[0.17-5.03,0.935]$ \\
\hline \multicolumn{5}{|l|}{ GSTP1 } \\
\hline AA & $35(43.75)$ & $48(51.06)$ & 1 & 1 \\
\hline $\mathrm{AG}$ & $36(45.00)$ & $39(41.49)$ & $0.79[0.42-1.48,0.462]$ & $0.83[0.32-2.15,0.697]$ \\
\hline GG & $9(11.25)$ & $7(7.45)$ & $0.57[0.19-1.67,0.303]$ & $0.62[0.14-2.76,0.526]$ \\
\hline
\end{tabular}

adjusted multiple logistic regression for partner's smoking, oral contraceptive use and HPV infection, b drop because of a zero count cell

inter-ethnic differences including behavioral risk factors might account for this discrepancy.

Decreased expression of GSTA1 in individuals with the TT genotype results in the accumulation of oxidative DNA damage, suggesting an altered potential for carcinogenesis of the GSTA1 polymorphism [34]; this explanation is quite reasonable. However, many conflicting results have been reported even for the same types of cancer; significant and not significant associations for bladder cancer [35-36] and colorectal cancer [37]. We failed to show an association between GSTA1 polymorphism and SCCA; the low $\mathrm{T}$ allele frequency requires a larger sample size to draw a conclusion. Since cancer types and ethnic backgrounds might underlie genetic predispositions, there remains room for the contribution of GSTA1 polymorphism to SCCA development.

The three genotypes of GSTM1 consistently showed significant risks of smoking with a lower OR for the Null individuals at around one -fourth of wild type homozygous individuals. Conflicting results of GSTM1 polymorphism and SCCA development [28] may be attributed to this fact. We simply expect that the lower enzyme activity results in the higher OR; however, in another deletion type polymorphism, GSTT1, OR for the individuals with Null genotype and with the wild type homozygous were similar to each other. This indicates the presence of possible intervention of compensatory effects by other GSTs. As for the GSTA1, the low T allele frequency may limit us to draw the conclusion with the present small sample size. In a study analyzing the same set of GST polymorphisms and colorectal cancer, the presence of GSTP1 Ile/Val (A/G) significantly decreased the risk of colorectal cancer [38], whereas the smoking risk was higher among heterozygous individuals than the Ile (A) homozygous individuals. It would be premature to conclude the presence or absence of genetic predisposition of GST polymorphisms in SCCA development.

A modified influence of the GSTT1 deletion on the association between combined (estrogen plus progestin) oral contraceptive use and sex hormone metabolism was demonstrated [39]. The use was also involved in cervical cell proliferation resulting in increased risks of cervical cancer [6]. The use of oral contraceptives possibly enhances HPV E6/E7 expression and thus results in HPV-related cervical cancer development [40].

In the current study, we investigated the possible role of the common GST polymorphisms in the development of cervical cancer in northeastern Thailand. The results showed that the genotypes GSTM1, GSTT1, GSTP1, and GSTA1 did not contribute independently towards cervical carcinogenesis; however, in the genotype-based sub population, the predisposition of smoking risk is related to the GST genotype. It is therefore suggested that knowing one's own genotype data will contribute to the prevention of cervical carcinoma by controlling risk habits.

\section{Acknowledgements}

This study was partly supported by (a) an Invitation Research Grant from Faculty of Medicine, Khon Kaen University, (b) a Research Fund from Khon Kaen University, and (c) JSPS Core University Program. The authors thank the staff and patients who took part in this study and Mr. Bryan Roderick Hamman for assistance with the English-language presentation of the manuscript under the aegis of the Publication Clinic, Research Affairs, Faculty of Medicine, Khon Kaen University. 


\section{References}

1. Bruni L, Barrionuevo-Rosas L, Albero G, Serrano B B, Mena M, Gómez D, et al. Human Papillomavirus and Related Diseases in the World. ICO/IARC Information Centre on HPV and Cancer (HPV Information Centre). Summary Report 27 July 2017.

2. Chaiwerawattana A, Sangrajrang S, Laowahutanont P, Petrith V, editor. Hospital-based cancer registry annual report 2015. Bangkok: Pornsup Printing; 2017.

3. Burd EM. Human Papillomavirus and Cervical Cancer. Clinical Microbiology Reviews. 2003 01;16(1):1-17. https:// doi.org/10.1128/cmr.16.1.1-17.2003.

4. Lodovici M, Bigagli E. Biomarkers of Induced Active and Passive Smoking Damage. International Journal of Environmental Research and Public Health. 200902 26;6(3):874-888. https://doi.org/10.3390/ijerph6030874.

5. Hoffmann DHI. THE CHANGING CIGARETTE, 1950-1995. Journal of Toxicology and Environmental Health. 1997 03;50(4):307-364. https://doi. org/10.1080/009841097160393.

6. Natphopsuk S, Settheetham-Ishida W, Sinawat S, Pientong C, Yuenyao P, Ishida T. Risk Factors for Cervical Cancer in Northeastern Thailand: Detailed Analyses of Sexual and Smoking Behavior. Asian Pacific Journal of Cancer Prevention. 2012 Nov 30;13(11):5489-5495. https://doi. org/10.7314/apjcp.2012.13.11.5489.

7. Pesch B, Kendzia B, Gustavsson P, Jöckel K, Johnen G, Pohlabeln H, Olsson A, Ahrens W, Gross IM, Brüske I, Wichmann H, Merletti F, Richiardi L, Simonato L, Fortes C, Siemiatycki J, Parent M, Consonni D, Landi MT, Caporaso N, Zaridze D, Cassidy A, Szeszenia-Dabrowska N, Rudnai P, Lissowska J, Stücker I, Fabianova E, Dumitru RS, Bencko V, Foretova L, Janout V, Rudin CM, Brennan P, Boffetta P, Straif K, Brüning T. Cigarette smoking and lung cancerrelative risk estimates for the major histological types from a pooled analysis of case-control studies. International Journal of Cancer. 2011 Dec 14;131(5):1210-1219. https:// doi.org/10.1002/ijc.27339.

8. Yu X, Zhang X, Dhakal IB, Beggs M, Kadlubar S, Luo D. Induction of cell proliferation and survival genes by estradiol-repressed microRNAs in breast cancer cells. BMC Cancer. 201201 20;12(1). https://doi.org/10.1186/14712407-12-29

9. Zhang X, Zhang L, Tian C, Yang L, Wang Z. Genetic variants and risk of cervical cancer: epidemiological evidence, metaanalysis and research review. BJOG: An International Journal of Obstetrics \& Gynaecology. 201402 19;121(6):664-673. https://doi.org/10.1111/1471-0528.12638.

10. Gorukmez O, Yakut T, Gorukmez O, Sag S, Topak A, Sahinturk S, Kanat O. Glutathione S-transferase T1, M1 and P1 genetic polymorphisms and susceptibility to colorectal cancer in Turkey. Asian Pac J Cancer Prev. 2016;17:3855-9.

11. Safarinejad MR, Safarinejad S, Shafiei N, Safarinejad S. Association of genetic polymorphism of glutathione S-transferase (GSTM1, GSTT1, GSTP1) with bladder cancer susceptibility. Urologic Oncology: Seminars and Original Investigations. 2013 Oct;31(7):1193-1203. https://doi. org/10.1016/j.urolonc.2011.11.027.

12. Hayes JD, Flanagan JU, Jowsey IR. GLUTATHIONE TRANSFERASES. Annual Review of Pharmacology and Toxicology. 200509 22;45(1):51-88. https://doi.org/10.1146/ annurev.pharmtox.45.120403.095857.

13. Li X, Pan J, Liu Q, Xiong E, Chen Z, Zhou Z, Su Y, Lu G. Glutathione S-transferases gene polymorphisms and risk of male idiopathic infertility: a systematic review and meta-analysis. Molecular Biology Reports. 2012 Dec 14;40(3):2431-2438. https://doi.org/10.1007/s11033-0122323-3.

14. Strange R, Fryer A. The glutathione S-transferases: influence of polymorphism on cancer susceptibility. IARC Sci Publ. 1999;148:231-49.

15. Coles BF, Chen G, Kadlubar F, Radominska-Pandya A. Interindividual variation and organ-specific patterns of glutathione S-transferase alpha, mu, and pi expression in gastrointestinal tract mucosa of normal individuals. Archives of Biochemistry and Biophysics. 2002 07;403(2):270-276. https://doi.org/10.1016/s0003-9861(02)00226-6.

16. Zimniak P, Nanduri B, Pikula S, Bandorowicz-Pikula J, Singhal SS, Srivastava SK, Awasthi S, Awasthi YC. Naturally Occurring Human Glutathione S-transferase GSTP1-1 Isoforms with Isoleucine and Valine in Position 104 Differ in Enzymic Properties. European Journal of Biochemistry. 1994 09;224(3):893-899. https://doi. org/10.1111/j.1432-1033.1994.00893.x.

17. Sundberg K. Differences in the catalytic efficiencies of allelic variants of glutathione transferase P1-1 towards carcinogenic diol epoxides of polycyclic aromatic hydrocarbons. Carcinogenesis. 199803 01;19(3):433-436. https://doi. org/10.1093/carcin/19.3.433.

18. Mannervik B, Helena Danielson U, Ketterer B. Glutathione Transferases-Structure and Catalytic Activit. Critical Reviews in Biochemistry. 1988 01;23(3):283-337. https:// doi.org/10.3109/10409238809088226.

19. Boar P, Coggan M, Johnston P, Ross V, Suzuki T, Webb G. Genetic heterogeneity of the human glutathione transfereses: A complex of gene families. Pharmacology \& Therapeutics. 1990 01;48(3):357-369. https://doi.org/10.1016/01637258(90)90054-6.

20. Fang J, Wang S, Zhang S, Su S, Song Z, Deng Y, Cui H, Wang H, Zhang Y, Qian J, Gu J, Liu B, Li P, Zhang R, Liu $\mathrm{X}$, Wang Z. Association of the Glutathione S-Transferase M1, T1 Polymorphisms with Cancer: Evidence from a Meta-Analysis. Onland-Moret NC. PLoS ONE. 2013 Nov 08;8(11):e78707. https://doi.org/10.1371/journal. pone. 0078707 .

21. Ateş NA, Tamer L, Ateş C, Ercan B, Elipek T, Öcal K, Çamdeviren H. Glutathione S-Transferase M1, T1, P1 Genotypes and Risk for Development of Colorectal Cancer. Biochemical Genetics. 2005 04;43(3-4):149-163. https://doi. org/10.1007/s10528-005-1508-z.

22. Safarinejad MR, Shafiei N, Safarinejad SH. Glutathione S-transferase gene polymorphisms (GSTM1, GSTT1, GSTP 1) and prostate cancer: a case-control study in Tehran, Iran. Prostate Cancer and Prostatic Diseases. 201101 18;14(2):105-113. https://doi.org/10.1038/pcan.2010.54.

23. Goodman MT, McDuffie K, Hernandez B, Bertram CC, Wilkens LR, Guo C, Seifried A, Killeen J, Le Marchand L. CYP1A1, GSTM1, and GSTT1 Polymorphisms and the Risk of Cervical Squamous Intraepithelial Lesions in a Multiethnic Population. Gynecologic Oncology. 2001 05;81(2):263-269. https://doi.org/10.1006/gyno.2001.6154.

24. Piao J, Shin M, Kweon S, Kim HN, Choi J, Bae W, Shim H, Kim H, Park Y, Choi Y, Kim S. Glutathione-S-transferase (GSTM1, GSTT1) and the risk ofgastrointestinal cancer in a Korean population. World Journal of Gastroenterology. 2009;15(45):5716. https://doi.org/10.3748/wjg.15.5716.

25. Natphopsuk S, Settheetham-Ishida W, Pientong C, Sinawat S, Yuenyao P, Ishida T, Settheetham D. Human Papillomavirus Genotypes and Cervical Cancer in Northeast Thailand. Asian Pacific Journal of Cancer Prevention. 
2013 Nov 30;14(11):6961-6964. https://doi.org/10.7314/ apjcp.2013.14.11.6961.

26. Natphopsuk S, Settheetham-Ishida W, Settheetham D, Ishida T. Lack of Participation of the GSTM1 Polymorphism in Cervical Cancer Development in Northeast Thailand. Asian Pacific Journal of Cancer Prevention. 201503 18;16(5):19351937. https://doi.org/10.7314/apjcp.2015.16.5.193.

27. Phuthong S, Settheetham-Ishida W, Natphopsuk S, Ishida T. Genetic Polymorphism of the Glutathione S-transferase Pi 1 (GSTP1) and Susceptibility to Cervical Cancer in Human Papilloma Virus Infected Northeastern Thai Women. Asian Pacific Journal of Cancer Prevention. 2018 02;19(2). https:// doi.org/10.22034/APJCP.2018.19.2.381.

28. Sobti R, Kaur S, Kaur P, Singh J, Gupta I, Jain V, Nakahara A. Interaction of passive smoking with GST (GSTM1, GSTT1, and GSTP 1) genotypes in the risk of cervical cancer in India. Cancer Genetics and Cytogenetics. 2006 04;166(2):117-123. https://doi.org/10.1016/j.cancergencyto.2005.10.001.

29. Saitou M, Ishida T. Distributions of the GSTM1 and GSTT1 Null Genotypes Worldwide are Characterized by Latitudinal Clines. Asian Pacific Journal of Cancer Prevention. 201502 04;16(1):355-361. https://doi.org/10.7314/ apjcp.2015.16.1.355.

30. Amtha R, R, Ching C, Zain R, Razak I, Basuki B, Roeslan B, et al. GSTM1, GSTT1 and CYP1A1. Polymorphisms and risk of oral cancer: a case-control study in Jakarta, Indonesia. Asian Pac J Cancer Prev. 2009;10:21-6.

31. Pakakasama S, Mukda E, Sasanakul W, Kadegasem P, Udomsubpayakul U, Thithapandha A, Hongeng S. Polymorphisms of drug-metabolizing enzymes and risk of childhood acute lymphoblastic leukemia. American Journal of Hematology. 2005;79(3):202-205. https://doi. org/10.1002/ajh.20404.

32. Stosic I, Grujicic D, Arsenijevic S, Brkic M, MilosevicDjordjevic O. Glutathione S-Transferase T1 and M1 Polymorphisms and Risk of Uterine Cervical Lesions in Women from Central Serbia. Asian Pacific Journal of Cancer Prevention. 201404 01;15(7):3201-3205. https:// doi.org/10.7314/apjcp.2014.15.7.3201.

33. de Carvalho C, da Silva I, Pereira J, de Souza N, Focchi G, Ribalta J. Polymorphisms of p53, GSTM1 and GSTT1, and HPV in uterine cervix adenocarcinoma. Eur J Gynaecol Oncol. 2008;29:590-3.

34. Akhdar H, El Shamieh S, Musso O, Désert R, Joumaa W, Guyader D, Aninat C, Corlu A, Morel F. The rs3957357C $>$ T SNP in GSTA1 Is Associated with a Higher Risk of Occurrence of Hepatocellular Carcinoma in European Individuals. Avila MA. PLOS ONE. 2016 Dec 09;11(12):e0167543. https://doi. org/10.1371/journal.pone.0167543.

35. Matic M, Dragicevic B, Pekmezovic T, Suvakov S, SavicRadojevic A, Pljesa-Ercegovac M, Dragicevic D, Smiljic J, Simic T. Common Polymorphisms in $<\mathrm{i}>$ GSTA $1</ \mathrm{i}>$, $<\mathrm{i}>$ GSTM1 $</ \mathrm{i}>$ and $<\mathrm{i}>$ GSTT1 $</ \mathrm{i}>$ Are Associated with Susceptibility to Urinary Bladder Cancer in Individuals from Balkan Endemic Nephropathy Areas of Serbia. The Tohoku Journal of Experimental Medicine. 2016;240(1):25-30. https://doi.org/10.1620/tjem.240.25.

36. Yu Y, Li X, Liang C, Tang J, Qin Z, Wang C, Xu W, Hua Y, Shao P, Xu T. The relationship between GSTA1, GSTM1, GSTP1, and GSTT1 genetic polymorphisms and bladder cancer susceptibility. Medicine. 2016 09;95(37):e4900. https://doi.org/10.1097/md.0000000000004900.

37. Deng Q, He B, Pan Y, Sun H, Liu X, Chen J, et al. Polymorphisms of GSTA1 contribute to elevated cancer risk: evidence from 15 studies. J BUON. 2015;20:287-95.

38. Hezova R, Bienertova-Vasku J, Sachlova M, Brezkova V,
Vasku A, Svoboda M, Radová L, Kiss I, Vyzula R, Slaby O. Common polymorphisms in GSTM1, GSTT1, GSTP1, GSTA1 and susceptibility to colorectal cancer in the Central European population. European Journal of Medical Research. 2012;17(1):17. https://doi.org/10.1186/2047783x-17-17.

39. Henningson M, Hietala M, Bågeman E, Olsson H, Jernström H. Interactions between oral contraceptive status and GSTM1 and GSTT1 deletions on insulin-like growth factor-1 (IGF-1) plasma levels in young healthy women. Growth Hormone \& IGF Research. 2010 Dec;20(6):432-437. https://doi. org/10.1016/j.ghir.2010.10.003

40. Chagas B, Gurgel A, Paiva Júnior S, Lima R, Cordeiro M, Moura R, Coelho A, Nascimento K, Silva Neto J, Crovella S, Freitas A. Synergic effect of oral contraceptives, GSTP1 polymorphisms, and high-risk HPV infection in development of cervical lesions. Genetics and Molecular Research. 2017;16(3). https://doi.org/10.4238/gmr16039742.

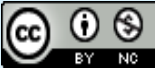

This work is licensed under a Creative Commons AttributionNon Commercial 4.0 International License. 